\title{
MORPHOLOGICAL CHARACTERIZATION OF ANCIENT AEOLIAN DUNES USING THE GROUND-PENETRATING RADAR, BOTUCATU FORMATION, SOUTHERN BRAZIL.
}

\author{
FERNANDA GUILARDI DA SILVA AND CLAITON MARLON DOS SANTOS SCHERER
}

\begin{abstract}
This paper presents ground-penetrating radar (GPR) profiles obtained from an aeolian dune of the Botucatu Formation. A 50 $\mathrm{MHz}$ antenna was used and an excellent resolution was achieved down to $10 \mathrm{~m}$ deep. GPR surveys have allowed a detailed reconstruction of the bed morphology. In the parallel to the foreset dip GPR section the reflectors that delineate the cross bedding are straight and steep whereas in the transversal section they are subhorizontal. This configuration indicates a bedform with straight to slightly wavy crestline (2D). Third- and first-order bounding surfaces were interpreted from the termination of the reflectors' sets. The presence of several third-order-bounding surfaces suggests either an aeolian dune subject to cyclical fluctuations of its height or reverse dune. The identification of a first-order bounding surface indicates climbing and accumulation of dunes in the studied area.
\end{abstract}

INTRODUCTION For long time sedimentologists have been dealing with the reconstruction of the morphology and behavior of aeolian dunes. A correct interpretation of ancient aeolian bedforms produces important information for both paleogeographic and paleoclimatic reconstructions as well as for the geometrical characterization of aeolian reservoirs. However, an accurate morphological reconstruction from the geological record is hindered by the scarceness of exposures good enough to allow the tridimensional visualization of the internal structure of paleodunes.

This paper intends to test a new method (GPR - Ground Penetrating Radar) to analyze internal structures and bounding surfaces of the aeolian dunes incorporated into the geological record. The term GPR stands for a technique that uses electromagnetic waves, with frequencies ranging from 10 to $1000 \mathrm{MHz}$, to map shallow subsurface structures and features (Davies \& Annan 1989). The energy radiated into the ground by GPR is reflected at interfaces where electrical properties change. The receiver antenna records the reflected energy. To use the GPR technique to perform the geometrical analysis of aeolian dunes one outcrop of the Botucatu Formation was chosen due to its lithological characteristics, i. e., the low content of clay minerals, a basic condition required by the method.

LOCATION AND METHOD The selected outcrop is located in Santa Catarina State, southernmost Brazil (Fig. 1). It allows the direct correlation of the GPR sections with laterally continuous exposures in which it is possible to carry out a detailed facies analysis.

Aiming to reach $20 \mathrm{~m}$ below the surface, $50 \mathrm{MHz}$ antennae were used. However, the water table acted as a barrier to the signal penetration, limiting the visualization of the reflectors to a depth of 10 $\mathrm{m}$. In spite of this physical constraint, it was possible to observe both cross-bedding and bounding surfaces. Data presentation follows the conventional seismic section, i. e., distance versus double time. A detailed description of GPR data processing is presented elsewhere (Silva 2000).

Only two GPR profiles, belonging to a larger database used in the MSc thesis of one of the authors, will be here detailed. Figure 1 shows the location and orientation of each profile within the study area. PG01 stands for the survey performed parallel and PG02 for the transversal to the foreset dip.

Most of each survey was performed on exposed, not altered rock hence allowing good lithological control for later correlation between rock and signal.

FACIES CHARACTERISTICS The outcrop studied comprises a single lithofacies, which is composed of fine- to coarse-grained, reddish pink, well-sorted sandstone displaying large-scale planar cross bedding. The cross-bedding set is at least $10 \mathrm{~m}$ thick and $150 \mathrm{~m}$ wide (dimension constrained by outcrop size) (Fig. 2a). In a plan view, foresets are straight and laterally continuous (Fig. 2b). The foresets have a mean dip of $24 "$ and a low dispersion of dip direction $\left(099^{\circ}\right.$ mean value).

Cross bedding is characterized by alternating wind-ripple and grain flow strata. Wind-ripple is the most common type of aeolian stratification, comprising from 90 to $95 \%$ of the outcrop. Wind-ripple deposits consist of fine- to coarse-grained sandstone and are thin, ta-

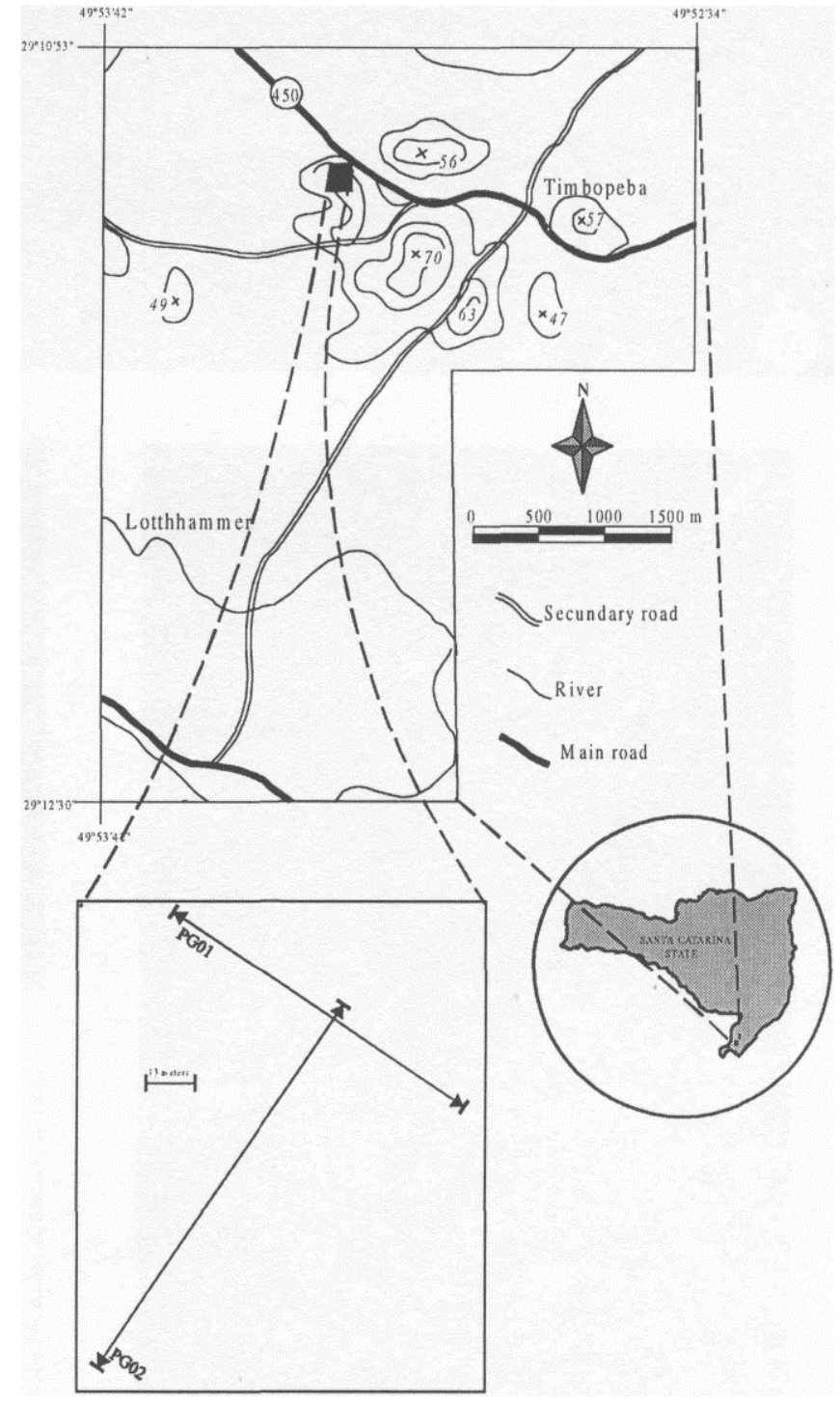

Figure I - The study sites and the distribution of GPR surveys referred to in this paper.

bular and laterally continuous strata. Each stratum ranges from 3 to 8 $\mathrm{mm}$ thick and presents inverse grading. Grain flow strata (5 to $10 \%$ of the outcrop) consist of medium- to coarse-grained sandstone and have a lenticular geometry (mean thickness of $4 \mathrm{~cm}$ ) in a transversal to foreset dip view. Grain flow strata occur either as homogeneous deposits or presenting an incipient inverse grading.

Third-order bounding surfaces (sensu Brookfield 1977) were identified as they bound cross-bedding bundles that have slightly 
different changes of dip direction (Fig. 2c). These surfaces range from straight to slightly curved and dip to the same direction, but at smaller angles than the cross bedding, resulting in smooth truncations. No other type of bounding surface (first- or second-order bounding surfaces) was observed in the analyzed outcrop.

RADAR PROFILES DESCRIPTION As mentioned, two radar profiles perpendicular to each other were acquired (Fig. 1). After processing, the PG01 and PG02 sections were interpreted, the graphic results presented in figure 3 . The reflectors in PG01 and PG02 sections materialize surfaces that bound sediment bodies with different dielectric properties that can represent physical or diagenetic changes.
In the radar section it is possible to identify the internal structure of the dune and recognize different types of depositional surfaces. The radar profile obtained along the foresets dip direction (PGO1), shows straight reflectors dipping from right to left (Fig. 3a), which can be correlated with sets of cross-stratification in the outcrop photograph (Fig. 2a). In the profile transversal to the foresets dip (PGO2) (Fig. 3b), these reflectors are sub-horizontal and parallel to each other.

The identification of third-order bounding surfaces was based on the termination of the reflectors that represent cross-strata, being more easily observed in the section parallel to the foresets dip (PG01). Third-order bounding surfaces bound truncated reflector sets. Cosets of cross-stratification with a larger third-order bounding surfaces can
A

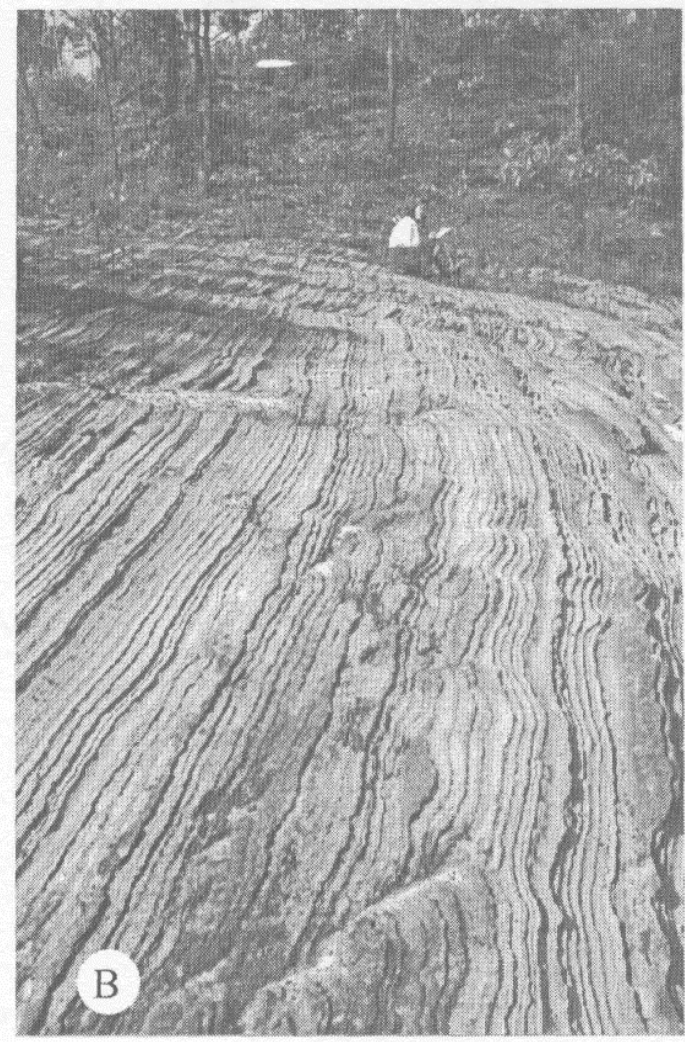

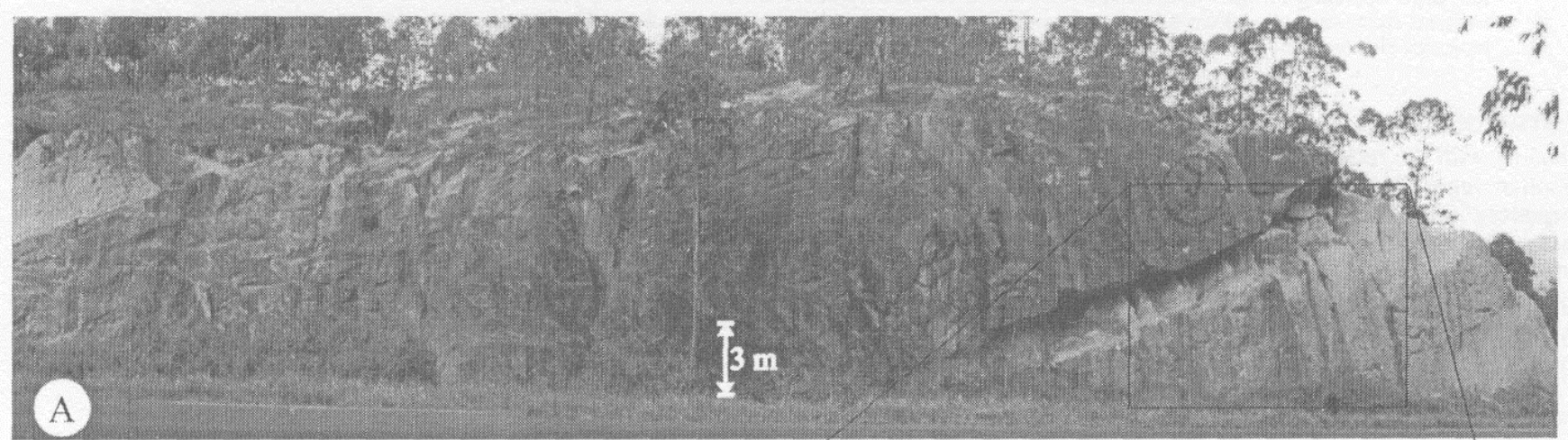
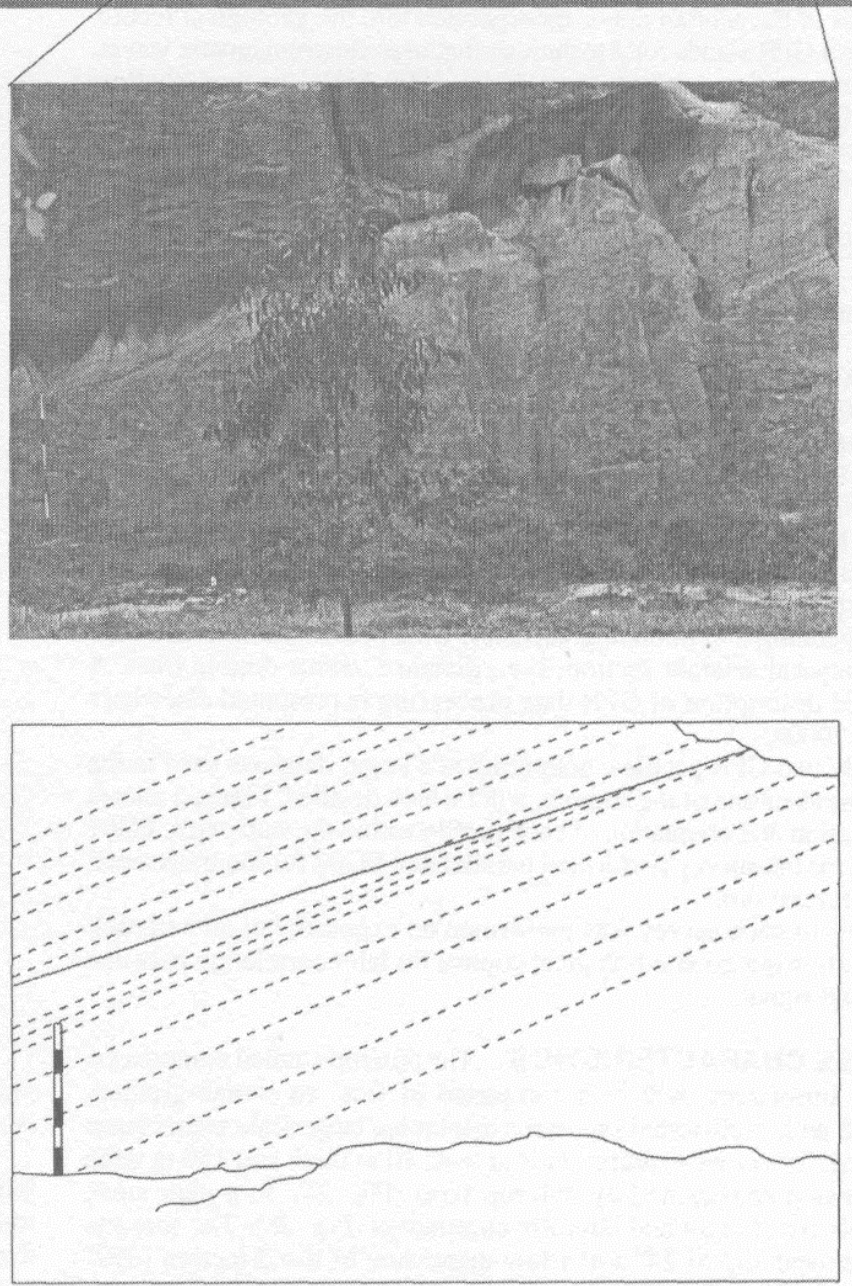

Third-order bounding surfaces

........ Foresets

C

Figure 2 - (A) Large-scale planar cross-bedded sandstone. (B) Photography illustrating foresets in plan view. (C) Third-order bounding surface separate crossbed sets. Bar scale - $3 \mathrm{~m}$. 
SE

NW
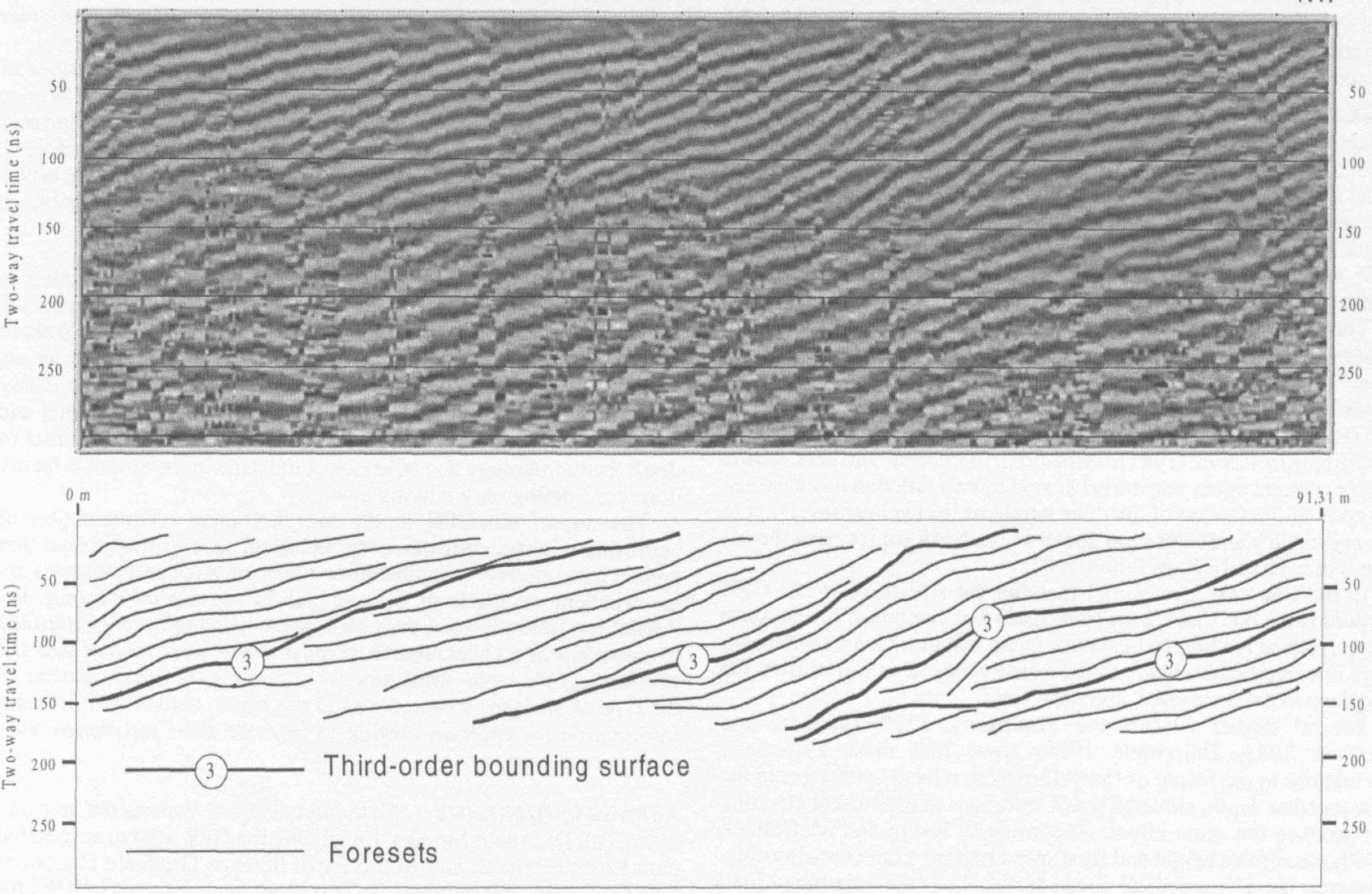

A

SW

NE
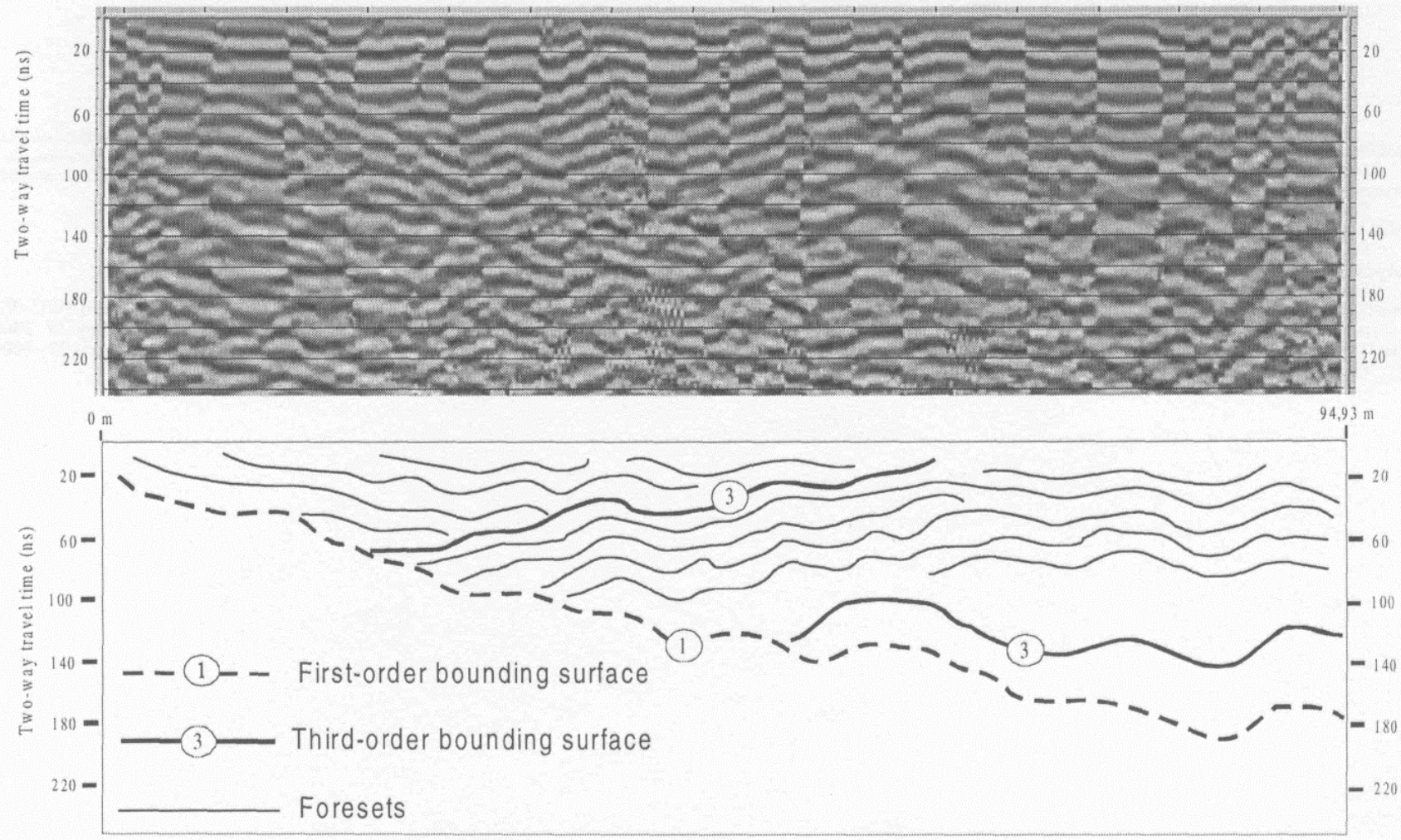

Figure 3 - (A) Radar section PGOl (above) and interpretation (below). This section is oriented to be approximately parallel to the foresets dip. (B) Radar section $P G 02$ (above) and interpretation (below). This section is oriented to be approximately transversal to the foresets dip. 
also be seen in the outcrop (Fig. 2c).

In the lower portions of PG02, it is possible to identify a truncating surface that can be followed for a long distance. This surface, which is slightly wavy and truncates both cross-strata and third-order bounding surfaces, interpreted as a first-order bounding surface, i. e., an interdune surface bounding two dunes.

DISCUSSION From the outcrop section and geometry of reflectors observed in both GPR sections it is possible to make some inferences about the dune morphology. The presence of planar crossstrata and plane bedding, in the sections parallel and transversal to the foreset dip, respectively, indicates that the deposits are related to the migration of simple bedforms with straight to slightly wavy crestline (2D), which include internal truncating bounding surfaces interpreted as third-order bounding surfaces.

The interpretation of a first-order bounding surface in the GPR sections indicates climbing and accumulation of dunes in the studied area. The occurrence of third-order bounding surfaces indicates depositional breaks and erosion of the dunes slipface (Brookfield 1977) closely related to the wind pattern in the area during deposition. According to Rubin (1987), third-order bounding surfaces within simple crescent dunes may be originated by two different mechanisms: (a) cyclical fluctuation of the dune height or (b) cyclical reversion of the asymmetry and migration speed of the bedform (reverse dunes) (see figure 16 and 22b in Rubin 1987).

In the first case, the model that fits the structures in the GPR sections is the one that results from small fluctuations of the bedform height, related to short term cycles. Dune height increases whenever there is a significant growth in the transference rate of sand from the interdune to the dune crest, and vice-versa.

Several studies (Rubin and McCulloch 1980, Boersma and Terwindt 1984, Dalrymple 1984) show that these systematic fluctuations in the height of macroforms are related to changes in the flow speed or depth, although small variations in the current direction can produce the same effect. According to Rubin and McCulloch (1980) macroform height and flow speed present a direct relationship. However, there is a critical speed from which the suspended load overpasses the bedload and consequently bedform height and flow speed start to have an inverse relationship.

On the other hand, whenever third-order-bounding surfaces are associated with fluctuations of the migration and asymmetry of the bedform, Rubin (1987) suggests a seasonal inversion of wind direction. Tidal flow inversions studied by Boersma and Terwindt (1981) generated frequent reactivation surfaces comparable to the erosion of the dune slipfaces and consequent formation of third-order bounding surfaces.

According to Rubin (1987), structures formed by fluctuations of bedform height can not be distinguished from those created by reverse dunes. In both cases, the cross strata and third order bounding surfaces present the same dip direction, as in the presented study. Therefore, it is a very difficult task to present a more specific model for the origin of the identified third-order bounding surfaces, being possible to related them to both previously mentioned processes.

SUMMARY AND CONCLUSIONS The GPR technique has registered reflectors which can be linked to bounding surfaces and cross-bedding of a dune of the Botucatu Formation, has reached about $10 \mathrm{~m}$ deep with excellent resolution. Third-order bounding surfaces are hardly noticed in the studied outcrop, although they can be easily visualized in the GPR sections. The acquisition of both parallel and transverse to foreset dip GPR profiles has allowed to reconstruct in detail the morphology and behavior of the dune in a way that is hardly done considering only outcrop data.

The use of the GPR in the morphological reconstruction of bedforms may be considered an excellent tool to understand and predict heterogeneity in hydrocarbon reservoir. Aeolian sandstones are an excellent reservoir of oil and gas in several basins (e.g. the Reconcavo Basin, Brazil), their heterogeneity being largely controlled by depositional architectures (Lindquist 1988). Data such as size and geometry of the cross-strata sets, in addition to the characteristics of the type of surfaces within the sand packages, constitute important information for engineers trying to increase fluid recoveries from aeolian reservoirs.

Acknowledgements To the Luiz Englert Foundation, in particular Prof. Dr. Adelir Strieder, for lending the GPR used to acquire the data here presented, and to the Earth Science Graduate Course of UFRGS for financial support. To two anonymous referees of RBG for the critical analysis of the manuscript

Boersma J.R. \& Terwind H.J. 1981. Neap-spring tide sequence of intertidal shoal deposits in a mesotidal estuary. Sedimentology, 28:151-170.

\section{References}

Brookfield M.E. 1977. The origin of bounding surfaces in ancient aeolian sandstones. Sedimentology, 24:303-332.

Dalrymple R.W. 1984. Morphology and internal structure of sandwaves in the Bay of Fundy. Sedimentolog, 31:365-382.

Davis J.L. \& Annan A.P. 1989, Ground Penetrating Radar for High-Resolution Mapping of Soil and Rock Stratigraphy. Geophysical Prospecting, 37:531 -551.

Lindquist S.J. 1988. Practical characterisation of eolian reservoirs for development: Nugget Sanstone, Utah-Wyoming thrust belt. Sedimentary Geology, 56:315-339.

Rubin D.M. 1987. Cross-bedding, bedform andpaleocorrets. Soc. Econ. Paleont. Mineral. Concepts Geol., $1,187 \mathrm{p}$

Rubin D.M. \& McCulloch D.S. 1980. Single and superimposed bedforms: a synthesis of San Francisco Bay and flume observation. Sedimentary Geology, 26:207-232.
Silva F.G. 2000. Caracterização morfologica e morfodinamica das dunas eolicas da Formacao Botucatu (Eocretdceo da Bacia do Parana) no sul de Santa Catarina. Porto Alegre, 176p. (Dissertafao de Mestrado, Institute de Geociências da Universidade Federal do Rio Grande do Sul).
Contribution IGC-081

Received February 25, 2000 Accepted for publication April 29, 2000 